\title{
Role of total reactive oxide ratios on strength development in activated fly ash
}

\author{
G.V.P. Bhagath Singh ${ }^{1}$, Kolluru V.L.Subramaniam ${ }^{2 *}$ \\ ${ }^{1}$ Research Scholar, Department of Civil Engineering, Indian Institute of Technology Hyderabad, \\ Hyderabad, India \\ ${ }^{2}$ Professor, Department of Civil Engineering, Indian Institute of Technology Hyderabad, Hyderabad, \\ India
}

\begin{abstract}
The role of individual reactive components and process variables such as molarity and temperature on alkaline activation of different lowcalcium fly ash is explored. The oxide ratios in the activated system, based on the total silica (total $\mathrm{SiO}_{2}$ ) in the system consisting of the reactive silica contributed by fly ash and the reactive alumina in fly ash are shown to provide consistent results for achieving the highest strength. For a given total $\mathrm{SiO}_{2}$ content in the system, an increase in the sodium content above a certain dosage does not influence the ultimate compressive strength. An optimum (total $\mathrm{SiO}_{2}$ ) to $\mathrm{Na}_{2} \mathrm{O}$ ratio, equal to 2.66 is established for achieving maximum strength. The role of temperature within the range of $60^{\circ} \mathrm{C}-85^{\circ} \mathrm{C}$ is not significant when the molarity of $\mathrm{NaOH}$ is high. A N-A-S$\mathrm{H}$ type gel with $\mathrm{Si} / \mathrm{Al}$ ratio ranging between 2.5 to 3.0 and the $\mathrm{Al} / \mathrm{Na}$ ratio varying between 1.30 to 0.9 is formed on decreasing the (total $\left.\mathrm{SiO}_{2}\right) / \mathrm{Na}_{2} \mathrm{O}$ ratio from 6.55 to 2.66
\end{abstract}

\section{Introduction}

Alkali activated binders can be made from aluminosilicate source materials. The most attractive aluminosilicate source material is fly ash due to its ready availability in a large quantity. Researchers have studied the influence of several factors on the compressive strength and the structure of alkali activated fly ash-based geopolymeric binders. The influence of the process variables, such as the temperature of curing and the oxide ratios of the activating solutions on the strength of activated fly ash have been evaluated.

Most commonly used activators are combinations of sodium hydroxide $(\mathrm{NaOH})$ and sodium silicate $\left(\mathrm{Na}_{2} \mathrm{SiO}_{3}\right)$, which are mixed in varying proportions. Most studies have focused on the influence of molarity of $\mathrm{NaOH}$ and the molar ratios of $\mathrm{SiO}_{2} / \mathrm{Al}_{2} \mathrm{O}_{3}$ and $\mathrm{Na}_{2} \mathrm{O} / \mathrm{Al}_{2} \mathrm{O}_{3}$ in the activating solution on the final strength of activated fly ash [1-4]. The compressive strength of activated fly ash increases with increasing concentration of $\mathrm{NaOH}$ in the activating solution [2]. $\mathrm{NaOH}$ primarily increases the molarity of the solution and also contributes the charge balancing cation, $\mathrm{Na}$. The addition of $\mathrm{Na}_{2} \mathrm{SiO}_{3}$ to the $\mathrm{NaOH}$ solution increases the strength of the geopolymer formed after the activation. The addition of $\mathrm{Na}_{2} \mathrm{SiO}_{3}$

\footnotetext{
${ }^{*}$ Corresponding author: kvls@iith.ac.in
} 
to the solution increases the $\mathrm{SiO}_{2} / \mathrm{Al}_{2} \mathrm{O}_{3}$ and the $\mathrm{SiO}_{2} / \mathrm{Na}_{2} \mathrm{O}$ ratios, and results in the formation of more $\mathrm{Si}-\mathrm{O}-\mathrm{Si}$ bonds in the final product [5,6]. Different values of $\mathrm{Na}_{2} \mathrm{SiO}_{3} / \mathrm{NaOH}$ in solution have been reported in the literature. $\mathrm{Na}_{2} \mathrm{SiO}_{3} / \mathrm{NaOH}$ ratio in the solution equal to 2.5 by mass has been considered to be suitable to produce stable fly ashbased geopolymer [7]. A $\mathrm{Na}_{2} \mathrm{SiO}_{3} / \mathrm{NaOH}$ ratio close to 2.0 were found to be suitable for producing the highest strength in fly ash-based geopolymer [8]. Highest strength in $\mathrm{NaOH}$ activated fly ash was obtained for $\mathrm{SiO}_{2} / \mathrm{Na}_{2} \mathrm{O}$ ratios in solution close to 0.69. [9]. The typical range of $\mathrm{Na}_{2} \mathrm{O} / \mathrm{Al}_{2} \mathrm{O}_{3}$ ratio in the geopolymer has been reported in the range of $0.25-0.3$ and it has been shown to vary with the type of binder $[10,11]$. There is a considerable variation in the findings reported in the literature since the solution ratios were arrived at considering one type of fly ash.

Fly ash contributes $\mathrm{Al}$ and $\mathrm{Si}$ to the reaction product, which is supplemented by the activators. Considering the product of the activation process, it has been shown that the strength of the material is enhanced if the $\mathrm{Si} / \mathrm{Al}$ ratio is higher in the product $[1,12]$. To achieve the desired elemental ratio in the end product, the activators required should consider the contribution of $\mathrm{Si}$ and $\mathrm{Al}$ contributed by fly ash. Since there is a large variability in the composition of fly ashes, the optimum solution ratios for one fly ash may not be applicable to a different fly ash since the reactive contents of the two fly ashes may be very different. Fly ashes with high reactive content would contribute higher quantities of $\mathrm{Si}$ and $\mathrm{Al}$ to the final product and may require a smaller addition of $\mathrm{Na}_{2} \mathrm{SiO}_{3}$. Activator solutions would have to be developed considering the composition and the reactive silica and alumina contents of fly ash.

Studies have shown that temperature of curing medium is another parameter that plays an important role in the geopolymerisation process [13-17]. In most of the cases researchers used the curing conditions of about $95 \%$ relative humidity and temperatures ranging from $30^{\circ} \mathrm{C}$ to $85^{\circ} \mathrm{C}[3,18-20]$. Along with these ratios, parameters such as water-to-geopolymer solids ratio, alkaline liquid-fly ash ratio and alkaline liquid-to-water ratio significantly influence the properties of fly ash based geopolymers [21].

An experimental study is conducted using two different low calcium siliceous fly ashes. The influence of sodium content, total reactive oxide ratios, temperature and $\mathrm{NaOH}$ molarity on strength development in the alkali activated fly ash is investigated. The influence of sodium is evaluated with reference to the total silica and total alumina in the activated system. The total silica in the activated system used for evaluation consists of the reactive silica contributed by fly ash and the activator solution. The influence of sodium content relative to the total reactive alumina contributed by fly ash and the total silica content of the activated system is evaluated.

\section{Materials and methods}

Two fly ashes, labelled B and N, were collected from a $500 \mathrm{MW}$ and a $2600 \mathrm{MW}$ thermal power plant located in Southern part of India. Both the fly ashes were collected directly from thermal power plants. The oxide composition of fly ashes were determined using X-ray Fluorescence spectroscopy (XRF) and are listed in Table 1. The sum may not be $100 \%$ due to the unreported oxide components which are present in trace quantities. Two fly ashes conforming to the requirements of siliceous fly ash as per the Indian Code of practice, IS 3812 [22] and Class F fly ash as per ASTM C 618 [23] with very low calcium contents.

Table 1. Oxide Composition (\% by mass) of fly ashes.

\begin{tabular}{|c|c|c|}
\hline Oxide & \multicolumn{2}{|c|}{ Fly ash Labels } \\
\cline { 2 - 3 } $\begin{array}{c}\text { Composition } \\
(\% \text { mass })\end{array}$ & $\mathrm{B}$ & $\mathrm{N}$ \\
\hline
\end{tabular}




\begin{tabular}{|c|c|c|}
\hline $\mathrm{CaO}$ & 2.75 & 3.51 \\
\hline $\mathrm{SiO}_{2}$ & 58.14 & 56.92 \\
\hline $\mathrm{Al}_{2} \mathrm{O}_{3}$ & 26.06 & 26.97 \\
\hline $\mathrm{Fe}_{2} \mathrm{O}_{3}$ & 7.32 & 6.13 \\
\hline $\mathrm{MgO}$ & 1.12 & 0.78 \\
\hline $\mathrm{K}_{2} \mathrm{O}$ & 2.17 & 2.77 \\
\hline $\mathrm{TiO}_{2}$ & 2.02 & 2.80 \\
\hline
\end{tabular}

A D2 PHASER (Bruker) benchtop automated diffractometer with $\mathrm{Cu}$-K $\alpha$-radiation equipped with LYNXEYE super speed position sensitive detector was used to measure the spectrum of the fly ash. Specimens for XRD were prepared using the back loading technique to minimize preferred orientation. Incident beam with Soller $2.5^{\circ}$ and $0.6 \mathrm{~mm}$ slit width and diffracted beam with Soller $4^{\circ}$ and $8 \mathrm{~mm}$ anti scatter slit width was used. Air scatter screen module over sample close to $2 \mathrm{~mm}$ was used to reduce the air scattering of the sample. The readings were taken in vertical Bragg-Brentano $(\theta-\theta)$ geometry between $10^{\circ}$ and $70^{\circ}$ at $0.02^{\circ}$ step size with 0.6 step per second, resulting in a total measurement time about 30 minutes per scan. In order to improve powder averaging and obtain accurate intensities, the samples were rotated at $15 \mathrm{rpm}$ during acquisition. The X-ray tube generator was operated at $30 \mathrm{kV}$ and $10 \mathrm{~mA}$. Quantitative phase analysis was performed using TOPAS 4.2 software with the. NIST SRM 676a $\alpha-\mathrm{Al}_{2} \mathrm{O}_{3}$ external standard method approach. Crystal structure of known phases were taken from Inorganic Crystal Structure Database [24].

The reactive silica and alumina contents were determined after subtracting the crystalline forms of Silica and Alumina in the form of Quartz and Mullite from the total oxide contents. The total amorphous content determined subtracting the sum of the weight fractions of crystalline phases from unity using procedure outlined by the authors [25] and the values are listed in Table 2 . It can be seen that the fly ashes used in this study have a low reactive silica content. The total reactive Alumina and silica in the two fly ashes are comparable. The reactive silica contents are lesser than the total Silica content.

Table 2. Main reactive oxide contents and Total amorphous content of fly ashes.

\begin{tabular}{|c|c|c|c|c|c|}
\hline $\begin{array}{c}\text { Composition } \\
\text { (\% mass) }\end{array}$ & $\mathrm{Al}_{2} \mathbf{O}_{3}$ & $\mathrm{SiO}_{2}$ & $\mathrm{Fe}_{2} \mathbf{O}_{3}$ & $\mathbf{C a O}$ & $\begin{array}{c}\text { Total amorphous } \\
\text { content (\%) }\end{array}$ \\
\hline $\mathrm{B}$ & 15.72 & 18.28 & 5.92 & 2.75 & 48.16 \\
\hline $\mathrm{N}$ & 14.82 & 17.72 & 4.23 & 3.51 & 46.73 \\
\hline
\end{tabular}

Sodium hydroxide and sodium silicate were used as an alkali activators to activate the fly ash. Sodium silicate solution was used to increase the soluble silica content in the system and the sodium content was adjusted using sodium hydroxide. Ratios of oxides for the activated system were calculated using the reactive alumina and the total silica (referred to as (total $\left.\mathrm{SiO}_{2}\right)$ ) consisting of reactive silica from fly ash and silica obtained from sodium silicate solution. The (total $\left.\mathrm{SiO}_{2}\right) / \mathrm{Na}_{2} \mathrm{O}$ ratio was varied without affecting the $\mathrm{Al}_{2} \mathrm{O}_{3} /\left(\right.$ total $\mathrm{SiO}_{2}$ ) ratio. For a given fly ash, the total reactive alumina content contributed by fly ash is fixed. The ratio of the (total $\mathrm{SiO}_{2}$ ) to the reactive $\mathrm{Al}_{2} \mathrm{O}_{3}$ content was kept constant with a value close to 2.0 in all mixes. The detailed experimental matrix is listed in Table 3 . The molarity of $\mathrm{NaOH}$ was determined using its concentration in water. Increase in the sodium content is achieved decrease in the Total $\mathrm{SiO}_{2} / \mathrm{Na}_{2} \mathrm{O}$ ratio, which leads to the increasing the molarity of $\mathrm{NaOH}$. 
Table 3. The Solution and Total reactive oxide mix ratio of alkali activated fly ashes.

\begin{tabular}{|c|c|c|c|c|}
\hline \multirow{2}{*}{$\begin{array}{c}\text { Fly ash } \\
\text { Label }\end{array}$} & \multirow{2}{*}{ Label } & \multicolumn{2}{|c|}{ Solution } & \multirow{2}{*}{$\begin{array}{c}\text { Total } \\
\text { SiO }\end{array}$} \\
\cline { 3 - 5 } & & $\mathbf{S i O}_{2} / \mathbf{N a}_{2} \mathbf{O}$ \\
\hline \multirow{4}{*}{$\mathrm{B}$} & $\mathrm{a}-\mathrm{XX}$ & 2.09 & Molarity $(\mathbf{M})$ & 6.55 \\
\cline { 2 - 5 } & $\mathrm{b}-\mathrm{XX}$ & 1.85 & 1.30 & 5.80 \\
\cline { 2 - 5 } & $\mathrm{c}-\mathrm{XX}$ & 1.51 & 1.90 & 4.72 \\
\cline { 2 - 5 } & $\mathrm{d}-\mathrm{XX}$ & 0.85 & 3.20 & 2.66 \\
\hline \multirow{3}{*}{$\mathrm{N}$} & $\mathrm{A}-\mathrm{XX}$ & 2.23 & 10.50 & 6.55 \\
\cline { 2 - 5 } & $\mathrm{B}-\mathrm{XX}$ & 1.97 & 1.00 & 5.80 \\
\cline { 2 - 5 } & $\mathrm{C}-\mathrm{XX}$ & 1.61 & 1.80 & 4.72 \\
\cline { 2 - 5 } & $\mathrm{D}-\mathrm{XX}$ & 0.90 & 3.10 & 2.66 \\
\hline
\end{tabular}

$\mathrm{XX}$ is 60 for curing at $60^{\circ} \mathrm{C}$. $\mathrm{XX}$ is 85 for curing at $85^{\circ} \mathrm{C}$

Total $\mathrm{SiO}_{2}=$ Reactive $\mathrm{SiO}_{2}$ (from fly ash) $+\mathrm{SiO}_{2}$ (from sodium silicate solution)

$\mathrm{SiO}_{2}=\mathrm{SiO}_{2}$ obtained from sodium silicate solution

$98 \%$ reagent grade sodium hydroxide pellets supplied by the SDFCL was used to prepare the solution. Sodium silicate with the density $1.44 \mathrm{~g} / \mathrm{cc}$ and with a chemical composition of $10.8 \% \mathrm{Na}_{2} \mathrm{O}, 30.5 \% \mathrm{SiO}_{2}$ and $41.3 \% \mathrm{H}_{2} \mathrm{O}$ supplied by kiran global chem limited was used. $\mathrm{NaOH}$ Solution was prepared with the required concentration of $\mathrm{Na}_{2} \mathrm{O}$ content. After 24 hours, solution was mixed with the sodium silicate solution. Fly ash was mixed with the premixed sodium silicate and sodium hydroxide solution using a pan mixer. The activator (the total mass of activating solution) to fly ash mass ratio was kept equal to 0.40 . Thorough mixing was performed till a uniform consistency of the paste was obtained. After mixing, the mix was poured into cube moulds. Cubes specimens of nominal dimensions $7 \mathrm{~cm}$ were prepared. All the samples were prepared at room temperature $\left(27 \pm 1^{\circ} \mathrm{C}\right)$. Immediately after casting, all specimens were cured in a sealed condition for 24 hours at room temperature before being subjected to further curing at elevated temperature and $95 \%$ relative humidity. Two different curing temperatures corresponding to $60^{\circ} \mathrm{C}$ and $85^{\circ} \mathrm{C}$ were used.

Compressive strength was measured from the cube samples at 3, 7, 14 and 28 days of age. Specimens were loaded up to failure at $2 \mathrm{kN} / \mathrm{sec}$ using a $3000 \mathrm{kN}$ compression test machine. After the completion of compression test, small samples were collected from the failed cube and ground to a smaller size $(<60 \mu \mathrm{m})$ using mortar and pestle. To stop the further reaction, samples was immersed and washed with isopropanol. The isopropanol was then evaporated at $40^{\circ} \mathrm{C}$. The samples were then stored in a desiccator over silica gel in a Nitrogen atmosphere until testing.

Image acquisition and elemental analysis was performed on alkali activated fly ash samples using a bench top Phenom Pro X Scanning Electron Microscopy (SEM) coupled with Energy Dispersive X-ray spectroscopy (EDS). The samples were placed on a carbon tape and attached to stainless steel stub. The acceleration voltage $15 \mathrm{kv}$ with the working distance $2 \mathrm{~mm}$ was used during the EDS analysis.

\section{Results and discussion}

The compressive strength of alkali activated fly ash $\mathrm{B}$ and $\mathrm{N}$ cured at $60^{\circ} \mathrm{C}$ with age is shown in Figure 1. Both the fly ashes exhibit similar tends in compressive strength at any particular age since the total (total $\mathrm{SiO}_{2}$ ) $/ \mathrm{Na}_{2} \mathrm{O}$ ratio is kept same for both the fly ashes, while there is a difference in the working solution ratios. Lower (total $\left.\mathrm{SiO}_{2}\right) / \mathrm{Na}_{2} \mathrm{O}$ ratio achieves higher strength than the higher the (total $\mathrm{SiO}_{2}$ ) $/ \mathrm{Na}_{2} \mathrm{O}$ ratio. For (total $\mathrm{SiO}_{2}$ ) $/ \mathrm{Na}_{2} \mathrm{O}$ ratio equal to 2.66, maximum compressive strength was achieved at 3 days after which there is very little 
improvement in compressive strength. In the mix with (total $\mathrm{SiO}_{2}$ ) $/ \mathrm{Na}_{2} \mathrm{O}$ ratio of 4.72 , there was a steady increment in strength till 7 days but the ultimate strength achieved is marginally higher than the (total $\mathrm{SiO}_{2}$ ) $/ \mathrm{Na}_{2} \mathrm{O}$ ratio 2.66 mix. After 7 days a very little improvement in strength and the ultimate strength is almost equal to the (total $\left.\mathrm{SiO}_{2}\right) / \mathrm{Na}_{2} \mathrm{O}$ ratio is 2.66 mix. The mixes with (total $\mathrm{SiO}_{2}$ )/ $\mathrm{Na}_{2} \mathrm{O}$ ratios equal to 6.55 and 5.80 show a steady improvement in strength till 28 days. The ultimate strength attained is however lower than the other two mixes. Results clearly indicates that for a given amount of total $\mathrm{SiO}_{2}$ in the system contributed by fly ash and $\mathrm{Na}_{2} \mathrm{SiO}_{3}$, the sodium content does not influence on the strength after certain dosage in the system. There is hence an optimum (total $\left.\mathrm{SiO}_{2}\right) / \mathrm{Na}_{2} \mathrm{O}$ ratio, which is close to 2.66 for achieving the maximum strength.
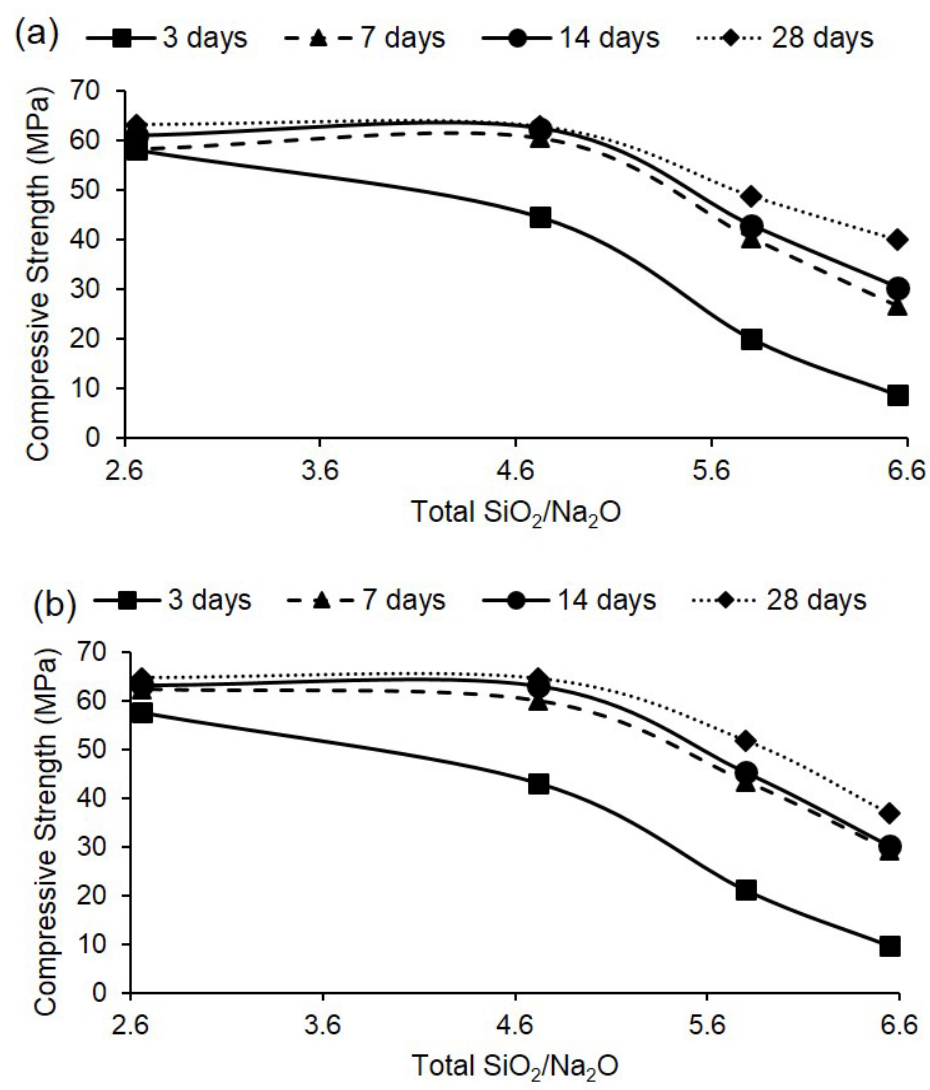

Fig. 1. Compressive strength of (a) Fly ash $\mathrm{B}$ and (b) fly ash $\mathrm{N}$ at any given age with (total $\left.\mathrm{SiO}_{2}\right) / \mathrm{Na}_{2} \mathrm{O}$ ratios cured at $60^{\circ} \mathrm{C}$.

The solution ratios of $\mathrm{SiO}_{2} / \mathrm{Na}_{2} \mathrm{O}$ at which (total $\mathrm{SiO}_{2}$ ) $/ \mathrm{Na}_{2} \mathrm{O}$ of 4.72 and 2.66 are achieved are different for the two fly ashes. Considering the molar oxide ratios in the working solution and the total reactive oxide composition ratios (given in Table 3), the results indicate that the reactive oxide composition ratios are higher than the working solution ratios. Comparing the two fly ashes, the ratio of $\mathrm{SiO}_{2} / \mathrm{Na}_{2} \mathrm{O}$ in the working solutions varied, but the total $\mathrm{SiO}_{2} / \mathrm{Na}_{2} \mathrm{O}$ ratio were kept identical. Nominally similar results are obtained in strength gain at identical ratio of (total $\mathrm{SiO}_{2}$ ) to $\mathrm{Na}_{2} \mathrm{O}$, while the working solution ratios were different. 
The compressive strength of the alkali activated mixes cured at $60^{\circ} \mathrm{C}$ and $85^{\circ} \mathrm{C}$ at 3 days and 28 days for both the fly ashes with age shown in Figure 2. Results indicate that both fly ashes showed nominally similar results at both curing temperatures. The compressive strength at both curing temperatures depends on the (total $\mathrm{SiO}_{2}$ ) $/ \mathrm{Na}_{2} \mathrm{O}$ ratio in the system. There is higher early strength and higher ultimate strength with decreasing the (total $\left.\mathrm{SiO}_{2}\right) / \mathrm{Na}_{2} \mathrm{O}$ ratio. For the mix with a (total $\left.\mathrm{SiO}_{2}\right) / \mathrm{Na}_{2} \mathrm{O}$ ratio of 2.66 , maximum compressive strength is achieved at the age of 3 days with very little additional improvement. Both the mixes attained identical ultimate compressive strength at both the curing temperatures. Mixes with (total $\mathrm{SiO}_{2}$ ) $/ \mathrm{Na}_{2} \mathrm{O}$ ratio equal to 6.55 and 5.80 showed steady increment in compressive strength; samples cured at $85^{\circ} \mathrm{C}$ showed higher strength than the samples cured at $60^{\circ} \mathrm{C}$ at any age. There appears to be an optimum ratio of the (total $\left.\mathrm{SiO}_{2}\right) / \mathrm{Na}_{2} \mathrm{O}$ in the range 4.72 to 2.66 , since increasing the sodium content within this range does not appear to improve the ultimate strength.
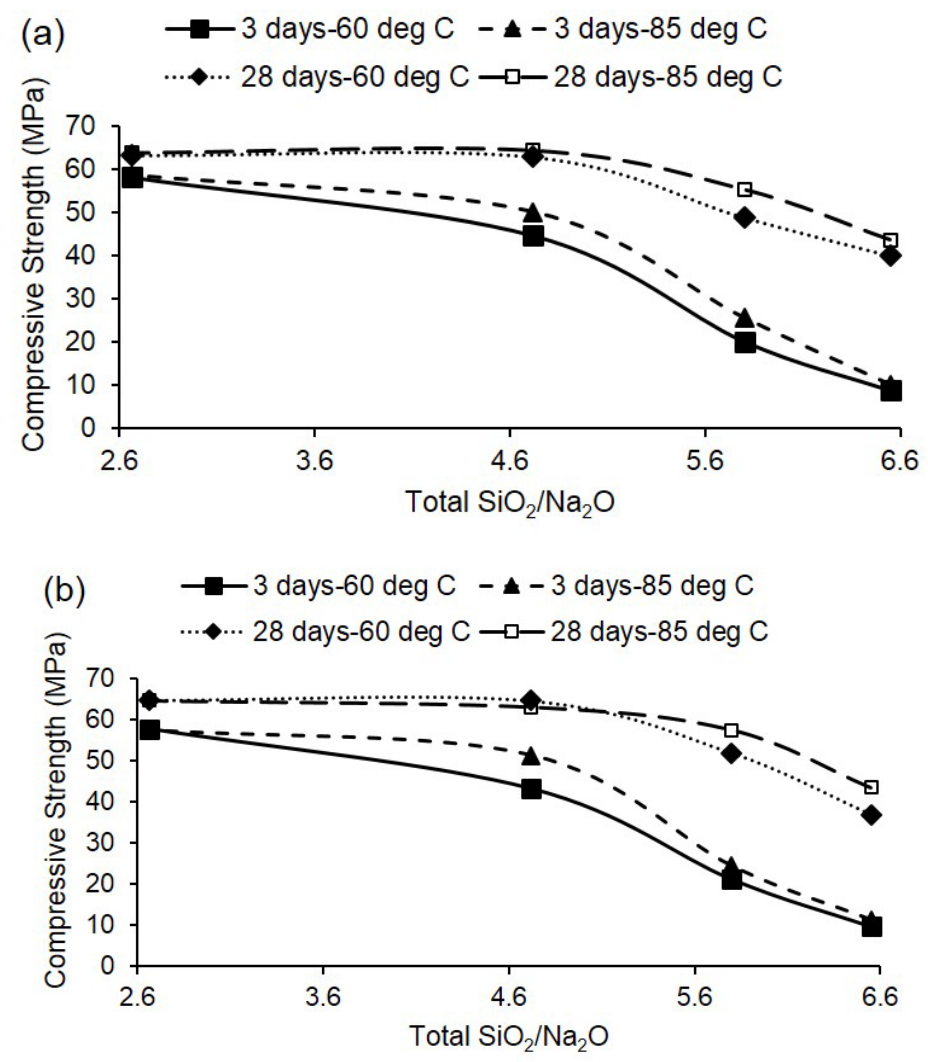

Fig. 2. Compressive strength of (a) Fly ash $\mathrm{B}$ and (b) fly ash $\mathrm{N}$ cured at $60^{\circ} \mathrm{C}$.and $85^{\circ} \mathrm{C}$ at any given age with (total $\left.\mathrm{SiO}_{2}\right) / \mathrm{Na}_{2} \mathrm{O}$ ratios

The experimental results indicate that the ratio of (total $\mathrm{SiO}_{2}$ ) $/ \mathrm{Na}_{2} \mathrm{O}$ ratio close to 2.66 achieves the highest compressive strength. Lower (total $\left.\mathrm{SiO}_{2}\right) / \mathrm{Na}_{2} \mathrm{O}$ ratio mixes attain a very high compressive strength by 3 days of age, and there is a small difference in the compressive strengths obtained from samples cured at the two temperatures. The results indicate that temperature has a greater influence on strength gain at higher (total $\left.\mathrm{SiO}_{2}\right) / \mathrm{Na}_{2} \mathrm{O}$ ratio. Near the optimum ratio of (total $\left.\mathrm{SiO}_{2}\right) / \mathrm{Na}_{2} \mathrm{O}$, the difference observed from the two curing temperatures is not significant. The sodium content is increased at the expense of increasing the Molarity with the addition of $\mathrm{NaOH}$. On increasing sodium content, the color of the 
product changes from light to dark. Typical photographs of failed specimens with total $\mathrm{SiO}_{2} / \mathrm{Na}_{2} \mathrm{O}$ ratios equal to 4.72 and 2.66 are shown in Figure 3(a) and 3(b), respectively. While the ultimate strengths of the two mixes were equal, a distinctive change in color of the product is discernible. Similar behaviour was observed at both the curing temperatures and in both the fly ashes. At higher molarity of $\mathrm{NaOH}$ (lower $\mathrm{SiO}_{2} / \mathrm{Na}_{2} \mathrm{O}$ ratios) the influence of temperature is not significant on the rate of strength gain.
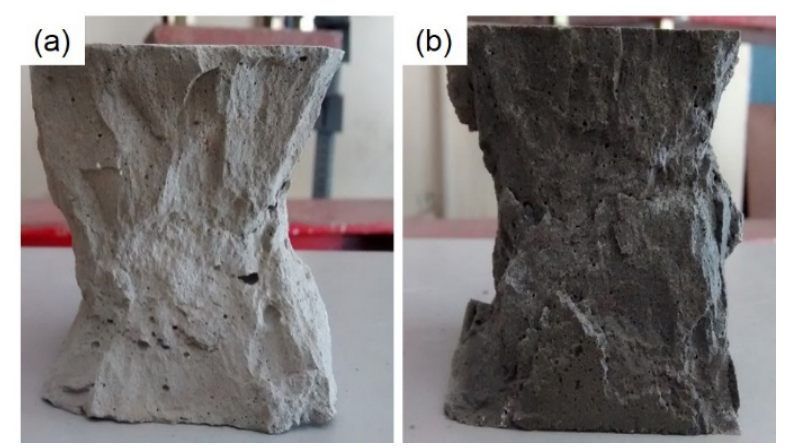

Fig. 3. Color change of the fly ash $\mathrm{B}$ product for (total $\left.\mathrm{SiO}_{2}\right) / \mathrm{Na}_{2} \mathrm{O}$ ratio (a) 4.72 and (b) 2.66 cured at $85^{\circ} \mathrm{C}$; at the age of 7 days.

Typical Backscattered image of the alkali activated (total $\mathrm{SiO}_{2} / \mathrm{Na}_{2} \mathrm{O}$ ratio equal to 4.72) fly ash B sample cured at $60^{\circ} \mathrm{C}$ at the age of 28 days are shown in Figure 4. The presence of partially reacted cenospheres from fly ash and crystalline phases are clearly identified. EDSbased spot and area analysis was performed on unreacted fly ash particle to determine the individual elements in the reaction product as shown in figure. The average values of $\mathrm{Si} / \mathrm{Al}$ and $\mathrm{Al} / \mathrm{Na}$ ratios of the all the mixes cured at $60^{\circ} \mathrm{C}$ for the both the fly ashes at the age of 28 days of age is listed in Table 4. Results clearly showed that the N-A-S-H type of gel with a $\mathrm{Si} / \mathrm{Al}$ ratio of 2.5 and $\mathrm{Al} / \mathrm{Na}$ ratio equal to 1.0 is formed in all the mixes with the variation in range.

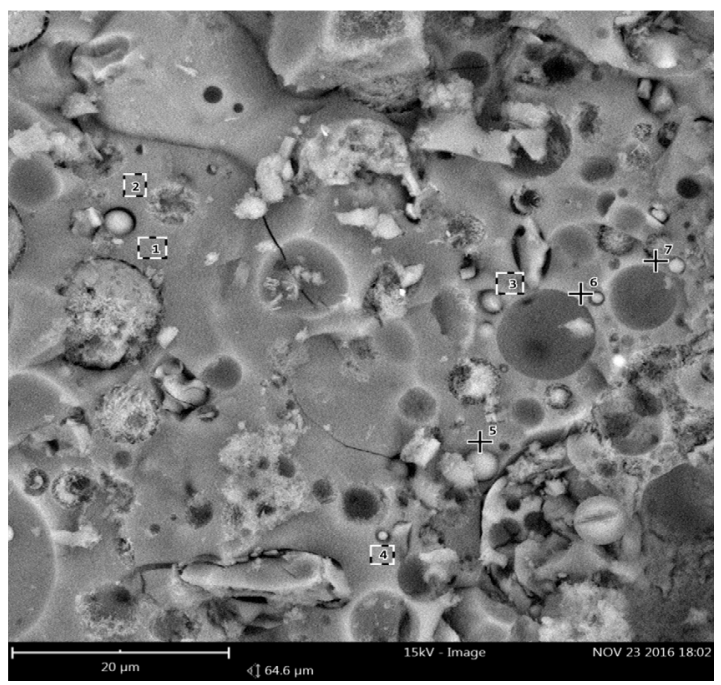

Fig. 4. SEM micrographs of Alkali activated (total $\mathrm{SiO}_{2} / \mathrm{Na}_{2} \mathrm{O}$ ratio is 4.72 ) fly ash $\mathrm{B}$ sample mix cured at $60^{\circ} \mathrm{C}$ at the age of 28 days. 
Table 4. EDS microanalysis (atomic data) of reaction product (mostly gel) around the reacted particle after alkali activated fly ash samples cured at $60^{\circ} \mathrm{C}$ at the age of 28 days.

\begin{tabular}{|c|c|c|}
\hline Label & $\mathbf{S i} / \mathbf{A l}$ & $\mathbf{A l} / \mathbf{N a}$ \\
\hline a-60 & 2.4 & 1.5 \\
\hline b-60 & 2.5 & 1.3 \\
\hline c-60 & 2.8 & 1.1 \\
\hline d-60 & 3.0 & 0.9 \\
\hline A-60 & 2.5 & 1.3 \\
\hline B-60 & 2.4 & 1.3 \\
\hline C-60 & 2.9 & 1.0 \\
\hline D-60 & 3.0 & 0.9 \\
\hline
\end{tabular}

\section{Findings and conclusions}

In this study the alkaline activation of low calcium fly ash using $\mathrm{NaOH}$ is investigated. Activator with varying proportions of $\mathrm{NaOH}$ and $\mathrm{Na}_{2} \mathrm{SiO}_{3}$ were used. The influence of oxide ratios (total $\mathrm{SiO}_{2}$ ) $/ \mathrm{Na}_{2} \mathrm{O}$ and $\mathrm{Al}_{2} \mathrm{O}_{3} /\left(\right.$ total $\mathrm{SiO}_{2}$ ) on the compressive strength of the activated fly ashes were evaluated. In calculating oxide ratios, the reactive Alumina and reactive silica obtained from fly ash were used. SEM with EDS indicate that the reaction products contain a N-A-S-H type gel. The oxide ratios derived using the reactive component contents of fly ash in the mix are important parameters on development of compressive strength of the paste. The ratios based on (total $\mathrm{SiO}_{2}$ ) $/ \mathrm{Na}_{2} \mathrm{O}$ ratios produce identical results. Highest strength are obtained for identical ratios of (total $\left.\mathrm{SiO}_{2}\right) / \mathrm{Na}_{2} \mathrm{O}$ for the two fly ashes used in the study, but the solution ratios are different. The sodium content in the solution does not influence the development of compressive strength of paste beyond certain dosage. The strength of the paste increases with the decreasing ratio of the (total $\mathrm{SiO}_{2}$ ) $/ \mathrm{Na}_{2} \mathrm{O}$ and the highest ultimate compressive strength is achieved for the ratio close to 2.66. The role of temperature within the range of $60^{\circ} \mathrm{C}-85^{\circ} \mathrm{C}$ is not significant at higher molarity. There is an insignificant difference in the compressive strength after 7 days of ages and at curing temperatures equal to $60^{\circ} \mathrm{C}$ and $85^{\circ} \mathrm{C}$.

\section{References}

1. A. Fernandez-Jimenez, A. Palomo, Composition and microstructure of alkali activated fly ash binder: effect of the activator, Cem. Concr. Res. 35, 1984-1992 (2005).

2. G.S. Ryu, Y.B. Lee, K.T. Koh, Y.S. Chung, The mechanical properties of fly ash-based geoploymer concrete with alkaline activators, Constr. Build. Mater.47, 409-18 (2013).

3. A Palomo, M.W Grutzeck, M.T Blanco, Alkali-activated fly ashes a cement for the future, Cem Concr Res 29, 1323-9 (1999).

4. Z Xie, X.Yunping, Hardening mechanisms of an alkaline-activated class F fly ash, Cem. Concr. Res. 31, 1245-9 (2001).

5. P. Duxson, J.L. Provis, G.C. Lukey, S.W. Mallicoat, W.M. Kriven, J.S.J. Van Deventer, Understanding the relationship between geopolymer composition, microstructure and mechanical properties, Colloids Surf. A. 269, 47-58 (2005).

6. M. Komljenovi, Z. Bascarevic, V. Bradic, Mechanical and microstructural properties of alkali-activated fly ash geopolymers. J. Hazard. Mater. 181, 35-42 (2010).

7. D. Hardjito, B.V. Rangan, Development and Properties of Low-Calcium Fly Ash based Geopolymer Concrete. Australia Curtin University of Technology, Perth, p.48, (2005). 
8. H.Y. Leong, D. E.L. Ong, J.G. Sanjayan, A. Nazari, The effect of different $\mathrm{Na}_{2} \mathrm{O}$ and $\mathrm{K}_{2} \mathrm{O}$ ratios of alkali activator on compressive strength of fly ash based-geopolymer Constr. Build. Mater. 106, 500-511 (2016).

9. M. Criado, A. Fernandez-Jimenez, A.G de la Torre, M.A.G. Aranda, A. Palomo, An XRD study of the effect of the $\mathrm{SiO}_{2} / \mathrm{Na}_{2} \mathrm{O}$ ratio on the alkali activation of fly ash, Cem. Concr. Res. 37, 671-679 (2007).

10. R. Fletcher, K. MacKenzie, C. Nicholson, S. Shimada, The composition range of aluminosilicate geopolymers, J. Eur. Ceram. Soc. 25, 1471-77 (2005).

11. M Rowles, B O'Connor, Chemical optimisation of the compressive strength of aluminosilicate geopolymers synthesised by sodium silicate activation of metakaolinite, J Mater. Chem. 13, 1161 - 65 (2003).

12. A. Ferna'ndez-Jime'nez, A. Palomo, I. Sobrados, J. Sanz, The role played by the reactive alumina content in the alkaline activation of fly ashes, Micropor Mesopor Mater. 91, 111-9 (2006).

13. A. Palomo, S. Alonso, A. Fernández-Jiménez, Alkaline activation of fly ashes: NMR study of the reaction products, J. Am. Ceram. Soc. 87, 1141 - 45 (2004).

14. P. Sukmak, S. Horpibulsuk, S.L. Shen, P. Chindaprasirt, C. Suksiripattanapong, Factors influencing strength development in clay-fly ash geopolymer, Constr. Build. Mater. 47, 1125-36 (2013).

15. M. Bing-hui, H. Zhu, C. Xue-min, H. Yan, G. Si-yu, Effect of curing temperature on geopolymerization of metakaolin-based geopolymers, Appl. Clay Sci. 99, 144-148 (2014).

16. Muhammad Talha Junaid, Amar Khennane, Obada Kayali, Arezki Sadaoui, Donald Picard, Mario Fafard, Aspects of the deformational behaviour of alkali activated fly ash concrete at elevated temperatures, Cem. Concr. Res. 60, 24-29 (2014)

17. William D.A. Rickard, Jadambaa Temuujin, Arie van Riessen, Thermal analysis of geopolymer pastes synthesised from five fly ashes of variable composition, Journal of Non-Crystalline Solids 358, 1830-39 (2012).

18. A Ferna'ndez-Jime'nez, A. Palomo, Characterization of fly ashes. Potential reactivity as alkaline cements, Fuel 82, 2259-65 (2003).

19. A Ferna'ndez-Jime'nez, I Garci'a-Lodeiro, A Palomo, Durability of alkali-activated fly ash cementitious materials, J Mater Sci. 42, 3055-3065 (2007).

20. M. Criado, A. Fernández-Jiménez, A. Palomo, Alkali activation of fly ash. Part III: Effect of curing conditions on reaction and its graphical description, Fuel 89, 31853192 (2010).

21. M. Talha Junaid, Obada Kayali, Amar Khennane, Jarvis Black, A mix design procedure for low calcium alkali activated fly ash-based concretes, Constr. Build. Mater. 79, 301310(2015).

22. Bureau of Indian Standards, Pulverized Fuel Ash-Specification, IS 3812-part 1:2003, Manak bhavan, New Delhi.

23. ASTM C 618, Standard Specification for Fly Ash and Raw or Calcined Natural Pozzolan for Use in Concrete.

24. ICSD, Inorganic Crystal Structure Database. 2013, Fachinformationszentrum: Karlsruhe, Germany.

25. G.V.P. Bhagath Singh, K.V.L. Subramaniam, Quantitative XRD Analysis of Binary Blends of Siliceous Fly ash and Hydrated Cement, J. Mater. Civ. Eng. 28, 04016042 (2016). 